University of Rhode Island

DigitalCommons@URI

Open Access Master's Theses

1986

\title{
A Physiologial Comparison of Two Rowing Ergometry Protocols on Performance in Male Oarsmen
}

Gregory M. Adams

University of Rhode Island

Follow this and additional works at: https://digitalcommons.uri.edu/theses

\section{Recommended Citation}

Adams, Gregory M., "A Physiologial Comparison of Two Rowing Ergometry Protocols on Performance in Male Oarsmen" (1986). Open Access Master's Theses. Paper 827.

https://digitalcommons.uri.edu/theses/827

This Thesis is brought to you for free and open access by DigitalCommons@URI. It has been accepted for inclusion in Open Access Master's Theses by an authorized administrator of DigitalCommons@URI. For more information, please contact digitalcommons-group@uri.edu. 
A PHYSIOLOGICAL COMPARISON OF TWO ROWING

\section{ERGOMETRY PROTOCOLS ON PERFORMANCE}

IN MALE OARSMEN

BY

GREGORY M. ADAMS

A THESIS SUBMITTED IN PARTIAL FULFILLMENT OF THE

REQUIREMENTS FOR THE DEGREE OF

MASTER OF SCIENCE

IN

PHYSICAL EDUCATION

UNIVERSITY OF RHODE ISLAND 
MASTER OF SCIENCE THESIS

OF

GREGORY M. ADAMS

APPROVED:

Thesis Committee

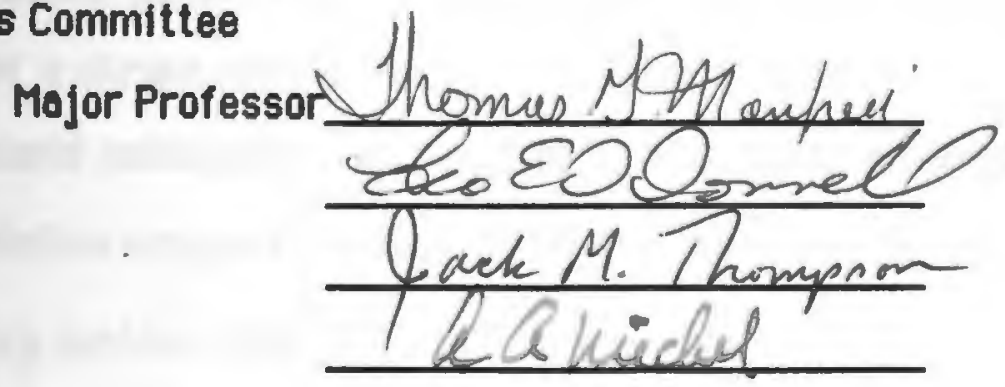

DEAN OF THE GRADUATE SCHOOL

UNIVERSITY OF RHODE ISLAND

1986 


\section{ABSTRACT}

The purpose of this study was to examine the effect of two strategically different protocols performed on the Concept II rowing ergometer, on the physiological response ond distence/time relationship in men's lightweight roce rowing. Ten members of the University of Rhode Island men's lightweight crew teom, eight of whom comprised the boot which won the 1984 Dad Vails Small College Chompionship, and two olternates volunteered for this study. Subjects performed a 3.5 mile "oll-out" (AO) rowing protocol designed to simulate the length, durotion, ond strotegy of troditional 2000 meter rowing race. Fourty-eight hours loter the subjects performed a second 3.5 mile protocol (P), designed to simulate the pocing strotegy recommended for most endurance type races. Rowing performance wos measured in elapsed time (min:sec) to complete the 3.5 mile protocols. Stroke rate (SR) was evoluated every thirty seconds (s) with the use of a stroke wotch, while metobolic efficiency was determined by thirty second colculations of heart rote (HR), absolute oxygen consumption $\left(\mathrm{VO}_{2}\right)$, relative oxygen consumption $\left(\mathrm{MVO}_{2}\right)$, ventilatory equivalent $\left(\mathrm{V}_{\mathrm{e}}\right)$, and respiratory quotient (RQ). Paired T-tests were epplied to the forementioned to determine possible significent differences between the two testing protocols .

Total time taken to complete the two testing protocols was not significontly different, and olmost identical between the tests. The meen time taken for completion being $379.6+-8.13$, and $380.3+-8.31$ seconds in the $A O$ and $P$ protocols, respectively. $S R$ for the $A O$ protocol wos significontly higher during the first 30 s ond significontly lower from the 
90 soint to completion of the test. HR in the AO test was wigher throughout the entire test, reoching significance ot the 30s, 150s, and 270 s marks. V02 was also higher throughout the entire AO test, reaching significance through the first 120s, and again ot the 240 s and 360 s marks. The averoge across all 30 s group mean values for SR, HR, absolute and relative V02, VCO2, and minute volume were significantly higher throughout the $\mathrm{AO}$ protocol.

A significant difference wos seen between the total energy costs of the two testing protocols, with the AO test cost being significantly higher. These difference, accompainied by almost identical times taken to complete the two tests, suggest that employment of the pacing strategy seen within the $P$ protocol may result in more efficient mechanisms and effective utilization of energy sources in the working muscles, and may result in a greoter use of "energy stores" over the lost severel hundred meters of 2000 meter race rowing. 


\section{ACKNOWLEDGEMENTS}

The outhor would like to thank the following:

Commitee members Or. Leo $0^{\circ}$ Donnell and Mr. Jack Thompson for their support and input to this project.

Dr. Robert Sonstroem for his statistical guidence.

Susan Lindholm for her insight into the sport of race rowing as well as her expert assistance with the laboratory testing.

Frank Miller for his assistence in preparing for my loborotory testing as well as with guidance in formulating my study design.

My parents for their continued support and motivation throughout this project.

Lastly, a special thank you to Or. Thomas G. Manfredi, Chairman of my Thesis Committee, for his support and guidence throughout this project. His dedication and committment to the exercise science field, and to the developement of the Humen Performance Laboratory ot the University of Rhode Island is unparrolleled. This committment has made my associotion with the Human Performance Laboratory an invaluable one. To the continued growth and committment towords his progrom this thesis is dedicated. 
I. 2 inimetion

II. REVIEW OF LITERATURE...........

Eorly ReG

Physical Characteristics of Dorsmen...................................... 9

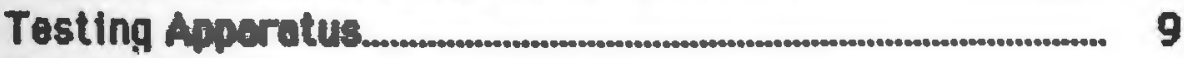

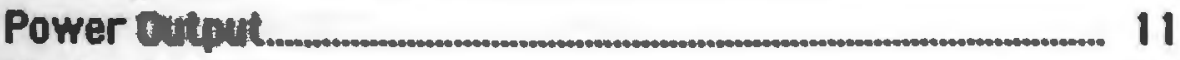

Mechanical Efficiency 12

Evaluating Energy Costs.................................................................... 12

Aerobic Impartance.......................................................... 13

Pacing Strategies During Rowing

Aerobic Metabolism of Dersmen............................................. 15

Absolute and Relative Terms................................................... 16

Oxygen Consumption During Rowing $\ldots$

Aerobic Capacitles.

Energy Costs of Rowing

Heert Rate. 20

Breothing Frequenc|

Puimonary Ventilation During Rowing............................. 21

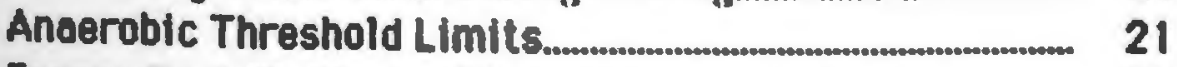

Energy Contributions of Anoerobic Metabolism................. 23

Corbon Dioxide Production................................................................ 25 
III. METHODOLOGY

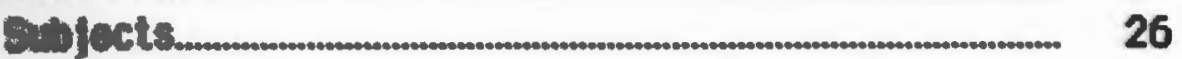

Study Desipn n.w.

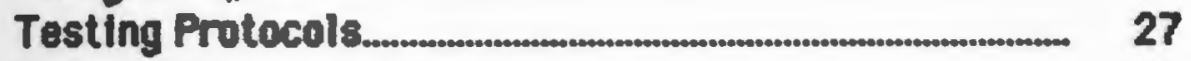

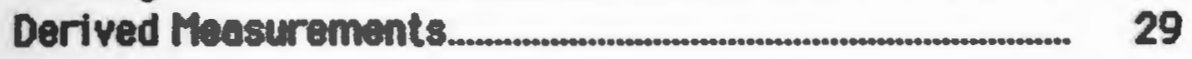

Physical Moesurements.......................................................n..... $\quad 29$

Physiologicol Moesurements.

Actuol Performence.

Stotisticol Analysis.

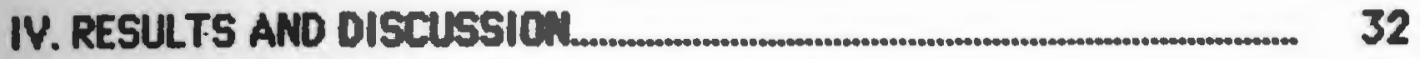

Physiological Cherocteristics............................... $\quad 32$

Testing Timo :

Stroke Rotes.

Heort Rote_non 39

Absolute Oxygen Consumption.............................................. 42

Relotive Oxygen Consumption......................................... 45

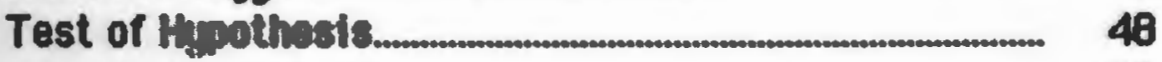

Precticol implicetions

Recommendetions for Future Reseerch.................................. $\quad 52$

Qneluatons _.

APPENDIX A Hydostotic Weighing Procedures ........................................ 54

BIQLIOGRAPHY 


\section{LIST OF TABLES}

PAGE

1. Physicol Cherorcteristics of Subject

2. Group Mean Performance and Physiological Doto.................. 34

3. Stroke

4. Heart

5. Absolute Oxygen Consumption.

44

6. Relative Oxygen Coneumption. 


\section{LIST OF FIGURES}

PAGE

1. Stroke Plotes 36

2. Heart Dave 39

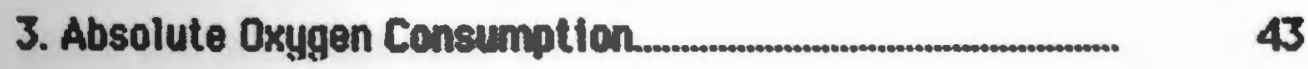

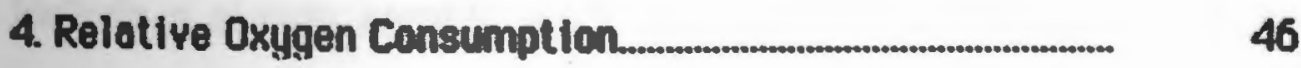




\section{CHAPTER |}

\section{INTRODUCTION}

Roce rowing has been determined to be one of the most demending competetive endurance sports (Hagerman, Hagerman, and Mickleson, 1979; Jackson and Secher, 1976). Exercise testing on rowers has shown that a high aerobic capacity is on important ingredient for international rowing success (Hogerman ot ol., 1976; 1979; Mohler ot ol., 1984; Secher et ol., 1982) with maximal aerobic capacities of oorsmen being among the highest recorded of any endurance athlete (DiPrampero et al., 1971; Jackson and Secher, 1976; Mahler et ol., 1984; Nowocki et ol., 1969).

Given the demands of a rowing regatta, which is 2000 meters in length for men, and lasts between six and seven minutes, a physiologically sound and efficient race strotegy should presumably be employed. This hes not been the case in rowing. Traditionally, oarsmen have violated recommended methods of pacing for endurence events which typically include a steady aerobic workload over the mojority of the race with an anaerobically based sprint over the final 45 to 60 seconds of the race (Hagerman et ol., 1979; Mahler et ol., 1964). Rowers, however, begín races ot extremely high energy expenditures and marked anaerobic response for the first 30 to 45 seconds followed by the body" of the race, which is at a slower steady state performance level for the middle 4 to 5 minutes of the race. This is followed by another anaerobic sprint over the last 45 to 60 seconds (Hagerman et al., 1972; Hogerman et al., 1979). Race rowing split times show the first 250 meters to be the fostest, with the following 250 meter segments covered in a slower split time and the last 250 meters 
being slightly faster (Hagerman et al., 1979). This strategy puts a preat stress on the oxygen transport systems and increases anaerobisis (Hogerman et al, 1972), which produces maximal lactate levels at the start of the race. This increase in aneerobisis occurs when the individual reaches his or her anaerobic threshold which is defined as being the point at which there is a non-linear increase in ventilatory equivalent/oxygen consumption (VE/V02), while ventilatory equivolent/carbon dioxide (VE/VCO2) remains unchanged (Wasserman et al., 1973). These maximal lactate levels must be endured for the duration of the race (Hogerman et ol., 1979).

Maximal stress testing to study oarsmen's physiologic capabilities has been done primarily on treedmill tests or on bicycle ergometers (Clerk et al., 1983; Secher et al., 1982) until the rowing ergometer was developed. Studies have found that the results obtained on the rowing ergometer closely simulate those during actual rowing (Hagerman ot al., 1979; Mahler et ol., 1984). Due to its specificity, however, the rowing ergometer has become the preferred method of exercise testing for oersmen (Cunninghem et ol., 1975; Hegermon et al., 1978, Hegerman et al.,1979; Mickleson ond Hagerman, 1982).

Physiological parameters have primarily been evaluated on two different protocols on rowing ergometers; o six-minute "all-out" (6M-AO) test, and o progressive, incremental (P) exercise test to exhoustion (Mahler et al. 1964). The 6M-AO test is used for its close approximation of intensity, duration, and racing strategy to competitive rowing (Hegerman et a1., 1978, Hogermen et al.,1979; Mahler et al., 1984). From o "standing start", each oarsmen rows the first ten strokes with maximal effort at a codence of 40 strokes minute ${ }^{-1}$. The stroke codence is then reduced to 
$34-36$ strokes $\cdot$ minute $^{-1}$ until the lost thirty seconds of the test when the stroke rote is increased to $40-42$ strokes - minute $^{-1}$ for the final sprint (Mahler et ol., 1984).

The P protocol corresponds to the traditional form of exercise testing seen during treadmill and bicycle ergometry tests (Mickleson ond Hagermon, 1982). Recently, Mahler et al., (1984), have compered and found no significant difference in peak $\mathrm{VO}_{2}$ or other peok physiologic porometers, with each test losting between six and seven minutes before exhoustion of the subject. Although each protocol has its odvantages, there has been no comperison of distance troveled through the different steges of an "all-out" test versus o "pocing" $(P)$ test following the recommended pocing strotegy of most endurance races. Since success in any roce is determined by the comparison of time needed to cover a set distence, a study of this distence/time relotionship seems in order. Understending of this distence/time relotionship between the $P$ test, which would seem more physiologically efficient, and the 6M-AO test, which simulates the traditional approech to racing, would seem to be imperative in developing o deeper understending of the physiologicol perometers that elicit optimal rowing performance.

\section{STATEMENT OF THE PROBLEM}

The purpose of this study was to examine the effect of two strategically different protocols performed on the concept II rowing ergometer, on the physiological response, and time/distence relationship in men's lightweight roce rowing. Ten members of the University of Rhode 
Island men's lightweight crew team volunteered for this study. Eight of the subjects comprised the boat which won the 1984 Dad Valls Small College Championship. The remoining two were alternates to that boat.

The ten-subjects performed a 3.5 mile "all-out" rowing protocol, designed to simulate the length, duration, and stategy of traditional 2000 meter race rowing. Forty-eight hours later the subjects performed a second 3.5 mile protocol, designed to simulate the pacing (P) strategy of most endurance type races.

Split times were taken at each .5 mile. Also, heart rate (HR), obsolute oxygen consumption (V02), relative oxygen consumption (MV02), ventilatory equivalent (Ve), fraction of expired oxygen (Fe02), froction of expired corbon dioxide (FeCO2), carbon dioxide production (VCO2), and respiratory quotient (RQ) were calculated every thirty seconds for each subject. In addition, body compositions were also obtained for each subject.

Each oarsman was evaluated on each protocol in a laboratory setting. Rowing performance was measured in elapsed time (min:sec) to complete the 3.5 mile protocols. Comparisons of each thirty second recordings of HR, V02, Ve, FeO2, FeCO2, VCO2, and RQ, were used to determine metabolic efficiency.

The following hypothesis were tested;

\section{HYPOTHESISI}

Subjects will achieve a faster time while rowing 3.5 miles using the pacing protocol as opposed to the traditional "all-out" protocol. 


\section{HYPOTHESIS II}

Mean heart rates will be higher in subjects performing the traditional "all-out" protocol when compared to the pacing protocol.

\section{HYPOTHESIS III}

The mean energy cost of the P protocol will be less than the "all-out" protocol as measured by mean absolute and relative oxygen consumption.

\section{DEFINITION OF TERMS}

For the purpose of this study, the following definitions were used:

Beathing Frequency - (BF) - The number of exhalations recorded per minute.

Eraction of Expired Corton Dioxide - (FeCO2) - The percentoge of expired air which is composed of certon dioxide.

Eraction of Expired Oxygen - (Fe02) - The percentoge of expired air which is composed of oxygen.

Heart Rate - (MR) - The number of times the heart beats in one minute.

Moximal Oxygen Uotake - (Y02 max) - The maximal amount of oxygen an individual can consume during physical work while breathing ot sea level. V02 max can be expressed in absolute (liters $\left.\cdot \min ^{-1}\right)$ and relative $(\mathrm{ml} \cdot \mathrm{kg}$. 
$\min ^{-1}$ ) terms.

Minute Ventilation - $\left(\right.$ Ve) - The volume of air expired in liters $\cdot$ minute ${ }^{-1}$.

Power Ten Strakes - The point or points in o rowing regatto in which the strake rate increeses and oll out effort is given on ten consecutive strokes.

Resnirotory Quotient - (RQ) - The relationship of the quantity of corbon dioxide produced to that of oxygen consumed. $(\mathrm{RQ}=\mathrm{VCO} 2 / \mathrm{VO2})$.

Stroke Rate - (SR) - The number of strokes performed per minute.

Yentllatory Equivalent - ( $\mathrm{Ve} / \mathrm{V02}$ - The rotio of minute volume to oxygen consumption.

\section{DELIMITATIONS}

This study wos delimited to :

1. A group of ten competitive mole oorsmen ranging from 18 to 25 years of age.

2. Physical and physiological meosurements which were performed in the Human Performance Laboratory at the University of Rhode island.

3. Subjects completing the same physical workouts on each testing day and on the days between testing. 


\section{LIMITATIONS OF THE STUDY}

The study wos limited in the following respects :

1. The study was limited to ten male voluteers of the University of Rhode Island's men's lightwelght crew team.

2. Subjects were near peak condition rather than at peak condition at the time of testing.

3. The order of administration of the $A O$ and P protocols was not randomized.

\section{BASIC ASSUMPTIONS}

It was assumed that all the oarsmen performed to maximal effort on each of the 3.5 mile testing protocols. 


\section{CHAPTER II}

\section{REYIEY OF LITERATURE}

Early Research

As early as 1920, Liljestrond and Lindherd descibed their attempts to measure oxygen consumption, heart rote and cardiac output during rowing. Hendersond and Haggard followed in 1925 with a study of estimated energy expenditure and power output of the 1924 Olympic eight oared crew gold medalists. Open spirometry was used to indirectly meesure oxygen consumption during and after ergometric work. Power output was determined by calculations using speed and weights while rowing o towred boat and by using a rowing ergometer of sophisticoted design which used on oar as a pump to move woter against a resistance The energy output of a typical oorsmen was reported to exceed by $30 \%$ to $60 \%$ the energy yield avallable through aerobic means. During the most strenuous workloads, on oorsmen produced oxygen deficits of between 4 and 6 liters. The outhors subjective judgement was that subjects in this study had not been exercised to maximal limits of their aerobic energy capacity (Henderson and Haggard, 1925). These studies, though primative when compared to today's methods and technology, opened the door to rowing research. Of equal importance, the innovation of these scientist as applied to testing apporotus, identified the importance of specificity of testing during actual performance, o procedure currently in use when meesurements of optimal performance are 
desired.

Physical Characteristics of Rowers

Internotional coliber oorsmen and oorswomen tend to be tall, muscular, and lean, with an age range that shows wide variobility, ronging from 18 to 36 years (de Gory et al.; 1974). Dorswomen are rather toll othletes with heovy skeletomusculer structure (Hebblenick et al., 1980). Meesurements collected on more than 600 oarsmen (Hogerman et al., 1979) have shown the overoge height of heovyweight oorsmen to be 192 centimeters with on overage body weight of $8 \theta$ kilograms. Percentage of fot in heovyweight oarsmen has shown o decline in recent years with reports of overages between 98 and 10 s.( Hogermon, 1984). An earlier study (Hogermon et al., 1979) reported on overage of $11 \%$ body fot for elite heovyweight oorsmen. Elite oorswomen overage 173 centimeters in height, weigh on overoge of 70 kilograms, and ronge between 128 and $25 \%$ body fot (Clarkson et al., 1983; Hagermon et al., 1979). Lightweight oarsmen tend to be very toll and lean, hoving only $7 \%$ to 8 \& body fot ( Hegerman, 1984).

\section{Testing Apporotus}

Bicycle ergometers were the eorliest testing opporatus used to evoluate physiological response during exercise in oorsmen (Agnerik et ol., 1967; Nui et al., 1966; Nowocki et al., 1969, 19710,b; Soltin and Astrond 1967; Yomokowo and ishiko, 1966). Groded exercise tests where v02 max was achleved at the end of exercise were used in many bicycle ergometer 
tests (Agnervik et al., 1967; Astrond, 1967; Nowacki et ol., 1969, 19710). This testing procedure using the bicycle ergometer as the testing opperatus was the method used on most highly trained athletes, regardless of the specific sport in which the othlete competed.

The meosure of physical working copocity in oorsmen using o rowing ergometer was first introduced in 1971 (Hagerman and Lee, 1971). A mechenically broked rowing ergometer wos used in most of the studies done in the United States becouse of Its mechanical operotion and task specificity (Horrison, 1967; 1970). A six minute test protocol was the designed exercise test in many of the early studies (Hogerman and Lee, 1971; Hagermen, 1975; Hagerman et al., 1972, 1975a, 1978; G. R. Hegerman, 1976). This design wos used as it closely simulates rowing on 8 oored boat over the standerd 2000 meter distence. A three minute protocol wos later designed and used to simulate a 1000 meter rece, usually rowed by women (Hegermon et al., 1979) in internationel regettes.

In more recent studles, (Hogermon and Mickleson, 1981; Mohler, 1983; Mahler et ol., 1983; Mickleson and Hegerman, 1982) a variable wind resistence rowing ergometer (Concept II, Morrisvill,VT) repleced the fixed resistence rowing ergometer explained by Hagerman et al. (1978) as the testing apperatus. The mojority of experienced oorsmen ond oorswomen pick the Concept II os the ergometer that best simulates actual rowing. Studies have been done recently on the Concept II, to colculate power output relative to velocity and stroke rotes performed during various intensities and durations of work (Hogerman and Mansfield, 1984).

The studies performed on the rowing ergometer produced slightly higher maximal aerobic copecity then these bicycle ergometer studies 
(Agnervik et al., 1967; Astrand, 1967; Nowacki et al.,1969, 19710). Localized muscular fatigue prior to the attainment of maximal working copacity has been the primary reason given for the depressed $\mathrm{VO}_{2}$ max values in cycle ergometry. Due to the noture of the six minute test most often used, peok V02 max velues were often recorded between the second and fourth minutes of exercise, rorely in the fifth, and never in the sixth and final minute of exercise (Hogermon et al., 1979; Mohler et al 1984).

Some studies hove utilized a greded treadmill exercise test to exhaustion and found $\mathrm{VO}_{2}$ max values equaled the highest $\mathrm{VO}_{2}$ meesured during simulated rowing (Carey et ol., 1974; Hagerman et al., 1975b). The differences in oxygen utllizotion in these types of tests have been attributed to differing total muscle masses involved (Hogerman, 1985). Though both rowing and cycling are weight supporting exercises involving extensive quadricep muscle group oction, treedmill running and rowing use the hemstring group to o greater extent (Hogerman, 1984).

This ottainment of physiological peek closely perrallels those found in recent six minute rowing ergometry studies and brings to question the unique pottern of pacing that rowers use during competition.

\section{Power Output}

Power output has been estimated for actual rowing (Celenteno et al., 1974; DiPrompero et al., 1971; Jackson and Secher, 1976; Orfelt, 1970; Secher, 1983) and measured during simulated rowing (Connors, 1974; Hegermen, 1975; Hegerman and Howle, 1971; Hagermen and Lee, 1971; Hegerman et al., 1972, 1975o, 1978, 1979; G. C. Hegermen, 1976; Polinski, 
1976; Willioms, 1976). Secher (1983) reported o power output of 386 watts ot recing speed in the direction of the boot, and 471 wotts totol, including work in the transverse direction becouse of the biomechenical noture of the rowing stroke. Lightweight men and women hove power outputs somewhat less then those of elite heovyweight oorsmen. An overoge of 370 wotts has been reported during a six minute simuloted exercise in lightweight men and on overage of 300 watts for women was recorded during 3 minutes of simulated rowing (Hagermen et al. 1979). Hogermen reported overage power outputs of $20 \mathrm{U}$. S. National Team members to be 390 watts with values ronging from 360 to 421 watts during six minute simulated rowing exercise.

Mechanical Efficiency

Mechanical efficiency has renged from $10 \%$ to $25 \%$ during simulated rowing (Connors, 1974; Cunninghom et al., 1975; D1Prompero et al., 1971; Hagerman et al., 1978, 1979; Jackson and Secher, 1976; Secher, 1983) and from 16 to 248 in actual rowing (Cunninghem et al., 1975; DiPrampero et al., 1971; Horrison, 1970; Secher, 1983). These findings of similarities in actual rowing and simulated rowing mechanical efficiencies support the use of rowing ergometry to adequately represent the task of rowing.

\section{Evaluating Energy Costs}

The measurement of humon energy expenditure ot rest and during physical activity has been of great interest over the years to scientists and athietes alike. Energy expenditure, or heat production has been measured in 
two woys; direct colorimetry and indirect colorimetry.

Direct celorimetry involves placing subject to be tested inside on air tight, thermally insulated chamber where heat production during the subjects activity can be evoluated. This method, though highly accurote, is impractical for evaluating energy costs during variuos sports, recreational, and occupotional activity. Indirect colorimetry is almost always the method used in these cases.

Indirect colorimetry is based on the fact that all energy metabolism depends on the utilization of oxygen. Thus, by meosuring on individual's oxygen consumption, an indirect estimate of energy metobolism con be obtained. Direct colorimetry studies hove shown that approximotely 4.82 $k c a l$ of heat are produced when a mixture of protein, carbohydrote, and fat is burned in one liter of oxygen. This value varies only slightly with even large variation of metabolic mixtures used os the energy source. For convenience of colculation, the value of $5 \mathrm{kcol}$ per liter of oxygen has been used for the indirect method of energy expenditure during studies involving all types of activity and exercise (McArdle et al, 1981).

Aerobic Importence

Studies during acute and chronic hypoxic exposure have magnified the importance of high levels of oerobic capacity to an oarsmen's performance (Hegerman, 1969; Hagermon et al., 1975b). More dysponoea-hypoio reloted physical collopses were reported during the rowing competition ot the 1960 Olympic games in Mexico City then for any other aerobic type event or sport. More than $\mathbf{8 0}$ incidents of physical collopse by oorsmen in the first 2 days, 
and several more during later races were reported by rowing offictols in Mexico City (Hagerman, 1969). Complete cessotion of a crew during competition is extremely rare in International Regattos and if so, is usually due to mechanical difficulties. Several crews in Mexico City stopped frequently and some failed to finish races ot the 1960 olympic Regatto. Hagermen et al., (1975) also reported significant effects on ventilatory adaptation in oarsmen following acute and chronic exposure to moderate oltitude.

Pacing Strategies During Rowing

Men's 2000 meter competitive race rowing has been previously established to be a predominately aerobically based exercise with aerobic metabolism yielding 758 to 858 of the totol energy cost (Connors, 1974 ). Given this energy demand, a physiologically sound and efficient racing strategy would presumably be employed. Ironically, this has not been the case. Traditionally, oarsmen have violated the recommended methods of pacing for endurance events: a steady aerobic workload over the majortty of the race with an anaerobically based sprint over the final 45 to 60 seconds of the race (Hagerman et al. 1979; Mahler et al. 1984). During traditional race rowing, oorsmen begin races ot extremely high energy expenditures and marked anaerobic response for the first 30 to 45 seconds before they settle of a slower steady rate of performance for the middle four to five minutes of the race. This is followed by another anaerobically based sprint over the last 45 to 60 seconds (Hagerman et al., 1972; Hogerman et al., 1979). Race rowing split times show the first 250 meters to be the fostest, with the 
following 250 meter segments covered in equal slower times with the lest 250 meters being slightly faster (Hagerman et al., 1979). This strotegy put - great stress on the oxygen tronsport system and increases onoerobisis (Hagerman et al., 1972), which produces maximal lactote levels ot the stert of the race. These lactate levels must be endured for the durotion of the race while inhibiting serobic performance (Hagerman et al., 1972).

\section{Aerobic Metebolism of Oarsmen}

Limited research wes conducted with oorsmen during the 1920's (Henderson and Haggard, 1925; Lil jestrond and Lindhard, 1920), ond not until the lote 1960's did physiological dato of oorsmen and oorswomen begin to oppear in scientific literature (Astrend, 1967; Astrond and Rodehl, 1977; Hagerman, 1969; Homby and Thomas, 1969; Hoy, 1968; Ishiko, 1967; Mellerowicz and Hansen, 1965; Nowocki et al., 1969; Soltin and Astrond, 1967). In 1967, high levels of eerobic copecity were reported in Swedish oersmen performing on bicycle ergometers (Astrond, 1967). The overage of these high levels of aerobic capacities ronked these oorsmen behind only biathletes, cross country skiers, and orienteering athletes. Saltin and Astrand (1967) studied the effects of maximol treedmill running and bicycle ergometry work on $\mathrm{VO}_{2}$ and heart rote in several highly conditioned athletes from the sports of canoeing and rowing. These subjects performed both arm and leg exercises on a specially designed bicycle ergometer. The oarsmen's maximal $\mathrm{VO}_{2}$ in liters per min compared fovorobly with the results achieved by the conoeists, cyclist, middle distence runners, and biathlon competitors, 
all achieving on overage $\mathrm{VO}_{2}$ max of 5.1 to 5.4 liters per minute. When oarsmen's $\mathrm{VO}_{2}$ max wos expressed in relotive terms, milliliters per kilogram per $\mathrm{min}(\mathrm{ml} / \mathrm{kg} / \mathrm{min})$, on average of $62 \mathrm{ml} / \mathrm{kg} / \mathrm{min}$ was obtained. This value was well below the meen values acheived for other endurance type athletes, reportedly due to consistently greeter body weights in the oorsmen.

Absolute and Relative Volues

Numerous studies have shown that maximal serobic capacities of elite oarsmen and oorswomen ore among the highest recorded (Di Prompero et al., 1970; Hegermen and Lee, 1971; Hegermen ot al., 1972, 1975。, 1978, 1979; Jackon and Secher, 1973, 1976; Larson and Forsberg, 1980; Mohler et al., 1983, 1984; Nowecki et ol., 1969, 19710; Soltin and Astrand, 1967; Secher, 1983; Secher ot al., 1982). Absolute $\mathrm{VO}_{2}$ max values have been measured in excess of 7 liters per minute $(1 / \mathrm{min})$ in 2 elite oersmen, and over $51 / \mathrm{min}$ in 3 females (Hagerman at ol., 1979). Translated to relative terms these values were over $80 \mathrm{ml} / \mathrm{kg} / \mathrm{min}$ for the men and over $70 \mathrm{ml} / \mathrm{kg} / \mathrm{min}$ for the women Lightweight oarsmen have ottained the highest relative $\mathrm{VO}_{2}$ max with volues exceeding $80 \mathrm{ml} / \mathrm{kg} / \mathrm{min}$ (Hegermen et al., 1979). Due to their body size and total muscle mass, lightweight oorsmen would be expected to achieve this greater $\mathrm{VO}_{2}$ max in relative terms while of the some time not reaching the obsolute values achleved by heovyweight oersmen.

Metobolic dato collected on more than 2000 oarsmen and oarswomen 
with international experience appears to indicate that if rowing athletes expect to become successful at this level, males should be able to achieve o $\mathrm{VO}_{2} \max$ of $6 \mathrm{l} / \mathrm{min}$ while females should be able to achieve a $\mathrm{VO}_{2}$ max of 4 1/min (Hagerman, 1984).

The fact that oarsmen's and oarswomen's weight is supported in the boat, seems to point toward absolute V02 max as the more relevant of the two measurements of oxygen uptake. The Germen Democrotic Republic uses such on objective criterion to ossist in identifying othletes with outstonding physiological capocities ( FISA Cooches Conference Report, Rome, Itoly, October 1980). Athletes from East Germany must be able to attain a $\mathrm{VO}_{2}$ max of $6 \mathrm{I} / \mathrm{min}$ and $4 \mathrm{l} / \mathrm{min}$ for men and women respectively to be considered for notional teem selection. This selection process ottempts to identify those othletes having one of the major components ot tributed to internotional rowing success; a highly developed oxygen transport ond delivery system.

Oxygen Consumption During Rowing

Oxygen consumption in rowers parallels the demands of the athlete on the oxygen tronsport system as is the case in all physical events. A cereful examination of the eerobic curve in oarsmen shows o unique response to a predominately eerobic event. With the exception of the first minute of exercise, oarsmen perform ot near maximal aerobic copacities for the entire duration of a six minute exercise test (Hagerman et al. 1979). The largest portion of o very high oxygen deficit is incurred during the first 30 to 90 
seconds of exercise ofter which they must call on their highly developed aerobic copecities to meet the energy requirements of the next four minutes (Connors, 1974; Hagerman et al., 1978: G. C. Hegerman, 1976; Polinski, 1976). Anaerobisis is called upon over the last 30 to 60 seconds when a boat's final all-out sprint to the finish occurs. This approach appears to elicit o rother inefficient approech to energy production.

An estimated oxygen cost of 46 liters was reported by DIPrampero et al., (1971) for rowing a paired boat over 2000 meters. This value was obtained during tank or basin rowing where water and current conditions are often less than optimal (Hagerman and Lee, 1971). Oxygen consumption during actual rowing was reported by Jackson and Secher (1976) with average $\mathrm{VO}_{2}$ values of between 5.8 and 6.0 liters per minute for a paired-oared crew during 7 to 8 minutes of strenuous work. These values supported the results of DiPrompero et al. (1971) but were somewhat higher then those oerobic values reported by Hogerman et al. (1984) in which o rowing ergometer was used. The relatively greater amount of work required during poired rowing as opposed to eight oarsmen shering the work load may explein these oxygen cost differences. It is also possible that the rowing ergometer slightly underestimates on oarsman's maximal oerobic capacity. Differences in boot length, weight, and design have all been mentioned as importent factors that may alter an oersman's energy production.

Aerobic Copacities

Studies on the aerobic copecities of rowers have consistently put them 
among the elite athletes in terms of achieving extremely high moximum $\mathrm{VO}_{2}$ values. Although this measure of $\mathrm{VO}_{2}$ max is helpful in assessing othletic potential and performance, rowers' most impressive physiological at tribute seems to be their ability to sustain extremely high percentages of their obsolute $\mathrm{VO}_{2}$ max even after they have exceeded their onoerobic threshold levels (Hogerman et al., 1978).

Energy Costs of Rowing

$\mathrm{VO}_{2}$ and velocity measurements of an elite poired- oored crew were used to calculate the metabolic cost of rowing at racing speed. An overage of 6.38 liters/minute wos reported (Jackson and Secher, 1973;) An oxygen cost continuem every ten years for race rowing from 1919 to 1979 was later shown using this same dota (Secher, 1983). Oxygen cost was reported to increese from a level of 5.1 liters/ minute in 1919 to 6.38 liters/minute in 1979. In 1925, Henderson and Hoggard had estimated 6.1 liters minute as the oxygen cost of rowing o competitive roce. This volue is equivalent to obout $30 \mathrm{kcol} / \mathrm{minute}$. Three energy yielding systems; oerobic, oneerobicalectic, and anoerobic loctic along with their relotive energy contributions to rowing were studied by Connors, 1974. Energy contributed by the serobic energy system was calculated from the net exercise $\mathrm{VO}_{2}$ measured during a six minute rowing ergometer test. Connors reported that $77.8 \%$ of the total energy expended during the six minute exercise was supplied by oerobic means. R-values were used to estimate the relotive kcol equivolent of 
oxygen consumption.

Mangaria's formula (Mangarla et al., 1963, 1964) wos applied to post-exercise venous blood lactic acid concentrations and indicated that glycolysis provided $4.1 \mathrm{kcol} / \mathrm{minute}$ or $13.8 \%$ of total energy expenditure. secher (1983) proposed a similar percentage of 148 attributed to anoerobic metabolism.

Heart Rote

Maximal heart rates for both men and women during simulated and actual rowing are similar and average between 190 and 200 beats/minute (Hagerman and Lee, 1971; Jackson and Secher, 1976; Secher et al., 1982). Heart rates have been sucessfully measured during training and competition (Hagerman and Lee, 1971; Ishiko, 1968; Jackson and Secher, 1976; Pruatt, 1977; Schneider, 1980). Oarsmen have averaged between 180 and 190 beats/minute for 6 to 8 minutes of exhaustive rowing (Cunningham et al., 1975; Hagerman, 1975; Hagerman and Howie, 1971; Hagerman and Lee, 1971; Hagerman et al., 1972, 1975a, 1978, 1979; Ishiko, 1968; Nut et al., 1966; Secher,1983: Williams, 1976). Heart rates have been monitored throughout progressive tests to determine anaerobic threshold heart rates. Rates of 160 to 170 have been consistently observed (Hagerman and Mickleson, 1981; Mahler, 1983; Mahler et al.,1983; Mickleson and Hagerman, 1982). These results would be useful in more accurately planning and monitoring training sessions so that the desired physiological training stimulus might be achieved. 
Breathing Frequency

Breathing frequencies generally average ot least 60 breaths/minute during both actual and simulated rowing. Peak levels of 80 to 85 breaths/minute have been recorded in some athletes (Hagerman et al. 1984). Darsmen appear to use cyclic breathing and breathe ot least twice during the cycle of each complete rowing stroke.

Pulmonary Ventilation During Rowing

Significant elevations in ventilation have accomponied the increases in oxygen uptake during simulated rowing. Measurements in excess of 240 liters/minute BTPS have been reported and excluding the first minute of exercise, most oorsmen overoge 200 liters/minute BTPS during both six minute ergometer rowing or actual rowing for the same time (unpublished dato, Work Physiology Laboratory, Onio University). Cramped body position of oarsmen during the catch phose of the rowing stroke has been suggested os the reason for a reduction of ventilatory equivalent $\left(\mathrm{V}_{6} / \mathrm{VO}_{2}\right)$ in oarsmen (Cunningham et al., 1975). Others have found no evidence to indicate a reduction of breathing frequency or an impairment of pulmonary ventilation (Clork et al., 1983; Hogerman, 1975; Hogerman et al., 1972, 19750, 1978, 1979).

Anaerobic Threshold Limits

A graded exercise protocol on the rowing ergometer has been used in 
recent studies for the purposes of determining both onaerobic threshold and $\mathrm{V}_{2}$ max. Graded exercise testing allows for a gradual increase in metabolic and cardiorespiratory activity. This gradual increase allows detection of the point where exercise intensity begins to exceed the capocity of the oxygen delivery system to sustain exercise. This progressive incremental exercise test allows the othlete to continue exercise in a stepwise foshion until $\mathrm{VO}_{2}$ is reached, sometime ofter the observation of the anaerabic threshold.

Anoerobic threshold, or on increase in anoerobisis, has most of ten been defined os the point in a groded exercise test at which there is a non-lineor increase in $\mathrm{V}_{8} / \mathrm{NO}_{2}$, while $\mathrm{V}_{8} / \mathrm{VCO}_{2}$ remains unchanged (Wassermon, Whipp, Koyol, and Beover, 1973). This progressive incremental testing procedure has olso elicited $\mathrm{VO}_{2}$ max results similer to the maximum or peok values of $\mathrm{VO}_{2}$ recorded during three and six minute rowing ergometer tests designed to simulate race conditions and not just an acceptable anaerobic measure of anaerobic threshold (Hogerman and Mickleson, 1981; Mahler, 1983; Mahler et al. 1983; Mickleson and Hagerman, 1982).

A great deal of controversy still surrounds the accuracy and meaning of aneerobic threshold meesurements. Recent studies (Hogerman and Mickleson, 1981; Mahler, 1983; Mohler et al., 1983; Mickleson and Hagerman, 1982) have reported aneerobic threshold meesurements that ore indeed estimates, but never the less provide useful information to athletes and cooches alike to better evoluate relative fitness levels and to determine troining intensities. Anaerobic thresholds of $85 \%$ to $95 \%$ of v02 max (Hagerman and Mickleson, 1981; Mahler, 1983; Mahler et al., 1983; Mickleson 
and Hagerman, 1982) attest to the very high aerobic capacities of rowing othletes.

Aneerobic threshold meosurements are most commonly reported os a percentage of $\mathrm{VO}_{2}$ max. In studies performed on oorsmen during the off season, measurements were significantly lower, 708 to 758 , then those meesurements taken only weeks before the World Rowing Championships, when they were reported at between $85 \%$ and $95 \%$ of $\mathrm{VO}_{2}$ max (Hogermon and Mickleson, 1981; Hegermon and Staron, 1983; Mickleson and Hagermon, 1982). In terms of enhencing performence, the increese in oxygen utilization could deloy the possible deleterious side effects of increasing lactic acid during high intensity exercise (Astrond and Rodohl, 1977; Hegerman et ol., 1978). An increased ability to utilize lactic acid as a fuel for exercise may be an importent attribute of the endurance trained athlete with high anaerobic thresholds (Orfelt, 1970; Spitzer, 1974). Utilization of lectic acid during o six minute rowing ergometer test reported by Hegermen et al., (1978) wos proposed since there was either a slight reduction or no change in this veriable rrom its peok concentration at the second minute of exercise until cessetion of exercise, despite significent involvement of the oneerobic energy system.

\section{Energy Contribution of Aneerobic Metebolism}

Aerobic metabolism os expressed by oxygen uptoke is o highly reliable messurement and hes been reported extensively in numerous studies. Aneerobic metobolism, on the other hand, is extremely difficult to assess. 
This relotive contribution of onoerobic metabolism to rowing has been estimated in o number of woys including the meosurement of oxygen deficit, oxygen debt, and the energy equivalent of post-exercise loctate concentrations (Connors, 1974; Hogermon et al., 1974, 1978; G. R. Hogermon, 1976; Polinski,1976). Consensus of theory would point toword oxygen deficit os being the best varioble to represent anoerobic metobolism, but due to difficulties in accurate colculations most investigators have ovoided this approach. Reported oxygen deficits have varied greatly and seem questionable. Volues ranging from 6 to 8 liters for both oorsmen ond oorswomen were reported by Hagermon et ol. (1979) while Secher et al. (1982) have reported larger volues. Oxygen debts, however, were somewhot higher and based on measuring $\mathrm{VO}_{2}$ for a 30 minute perlod following o six minute and three minute simulated rowing exercise for men and women respectively. Hogermon et $\mathrm{ol}$. (1978) reported Oxygen debts os high as 20 liters for internotional caliber oorsmen with on overoge of 13.5 liters. Secher et ol., (1982) reported o maximal volue of 33 liters. Oxygen debts meesured on oarswomen and lightweight men have been reported as 10 and 12 liters respectively (Hogerman et ol. 1979).

Blood loctote levels also signify oneerobic energy involument. Meximum venous blood loctote concentrotions have been reported to ronge from 14 to $18 \mathrm{mmol} / 1$ iter following six minute simuloted rowing in both elitelightweight and heovyweight oorsmen. Exhoustive treodmill running produced $11 \mathrm{mmol} / 1$ iter in oorsmen ond o ronge of 15 to $17 \mathrm{mmol} / 1$ iter wos seen immediately ofter notional and international rowing competition (Vaage, 1977). Concentrations for women averaged $16 \mathrm{mmol} / 1$ iter following three minutes of simulated rowing (Hogermon et al., 1979). These high 
levels of blood lactate concentrations signify significant anaerobic energy involvement during competitive rowing.

Corton Dioxide Production

Carbon dioxide is a direct bi-product of the chemical chain reaction involyed in energy liberation and utilization. With increasing amounts of energy expenditure, on increasing amount of corbon dioxide is produced. This carbon dioxide must be transported to the lungs where the exchenge of corton dioxide and oxygen takes place. Oxygen is consumed for sustained energy production os carbon dioxide is released and exhaled to the outside atmosphere.

Carbon dioxide production can be o useful tool in monitoring energy releasing chemical reactions during exercise. The greater omount of corbon dioxide on individual produces reflex a greater amount of energy producing chemical reactions taking place within the individual. 


\section{CHAPTER III}

\section{METHODOLOGY}

Supjects

Ten members of the University of Rhode Islend's 1984-85 men's lightweight crew team volunteered to participate in this study. These subjects were the eight members that comprised the boat which won the 1984 Dad Voils Regatta, making them national small college champions, and two alternates. Prior to any testing, subjects were given - brief explanotion of the study and its purpose.

\section{Study Design}

All testing was performed during the third week of Februory, 1985, in the Human Performance Laboratory ot the University of Rhode Island. All subjects were given o general overview of the procedures prior to the initiation of any testing. Hypothesis and specifics of testing protocols were not discussed with the subjects. Prior to their first exercise testing session, subjects were scheduled for body composition assesments. Hydrostatic weighing was the technique employed.

When subjects arrived for their first exercise testing session, they were asked to read, complete, and sign on informed consent statement and o 
verbal medical history evaluation was performed. Each subject's height and weight were then token ond recorded just prior to being prepered for a $\mathrm{CM}-5$ EKG configurotion. Resting heart rote and blood pressure were measured and recorded.

Forty eight hours ofter each subject completed his first testing session, he returned to perform the second exercise test. Times were kept consistently forty eight hours aport with individuals hoving identical testing circumstances on each day. All subjects completed the some troining sessions during the testing week.

\section{Iesting Protocols}

On the first visit to the Human Performence Laboratory, each subject performed the first of two distinctly different exercise tests on the Concept II rowing ergometer. This "all-out" (AO) test wos designed to simulate the duration, intensity, and racing strategy of a competitive 2000 meter rowing race. This (AO) protocol wos a modified version of the "oll-out" protocol described by Mohler et ol. in the December 1984 issue of Medicine and Science in Sport and Exercise.

Each subject performed a five minute worm up on the Concept II rowing ergometer ot a flywheel speed of twenty-two mph, (35 kpm). After this worm up, eech subject wos given of five minute rest os he received instructions from his coxswain on the exercise test that would follow.

Each subject was coaxed through his customary start from the stationary position of $3 / 4$ slide, $1 / 2$ slide, $3 / 4$ slide, $4 / 5$ slide, $5 / 6$ slide, full silde, followed by 20 full strokes of moximol effort at a stroke rote 
codence of 36 strokes per minute. The stroke rote wos then reduced to a cadence of 30 strokes per minute until the three mile mark, where the subject was coaxed for his final all-out sprint over the last .5 mile.

After o forty eight hour period, in which all subjects completed the exact training sessions, subjects returned to perform the second exercise testing protocol. This Pacing $(P)$ protocol was designed to follow the generally employed strotegy in most exercise events of the aerobic type.

Each subject agoin performed a five minute warm up on the Concept II rowing ergometer at oflywheel speed of twenty-two mph, (35 kpm). After this worm up, the subject was given of five minute rest os he received instructions from his coxswain on the exercise test that would follow.

Each subject was again coaxed through his customary start from the stationary position of $3 / 4$ slide, $1 / 2$ slide, $3 / 4$ slide, $4 / 5$ slide, 5/6 slide, full slide, followed by 20 full strokes of maximal effort at a stroke rote cadence of 32 strokes per minute. The stroke rote was then reduced to a codence of 31 strokes per minute until the three mile mark, where the subject wos cooxed for his final all-out sprint over the last .5 mile.

Two sets of power ten strokes were also performed by each oarsmen in each exercise testing protocol. These power tens were done ot a cadence of two strokes per minute faster then the settle stroke rate in the body of the given protocols, or at 32 strokes per minute in the "oll-out" protocol and 33 strokes per minute in the pacing protocol. These strokes were done ot the 1.5 and 2.3 mile marks in each of the two protocols which simulates closely the points in a rowing race where power tens are usually performed. 


\section{Deriyed Measurements}

Derived meosurements include percent body fat from hydrostatic weighing and stroke rate from stroke watch reading.

\section{Physical Measurements}

Height was recorded to the nearest quarter of an inch, and weight was recorded to the nearest quarter of a pound on a physician's scole.

Percentage of body fot was evaluated with the hydrostatic weighing procedure described by Kotch and Katch, 1984. (Appendix A) This procedure was performed in the Tootell Aquatics Center utilizing the competitive diving pool os the underwoter weighing tank.

\section{Physiological Measurements}

Physiologic and metabolic dato were obtained using the Erich Jeager Ergo Pneumotest equipped with o Hewlett Pockard Dato Spir Junior. The gas onolyzer is equipped with o two-way modifled Wilmore-Costill breathing valve, oxygen and carbon dioxide analyzers, o pneumotacograph for volume measurements, and a computer assisted assembly for on line thirty second metabolic calculations of absolute oxygen consumption $\left(\mathrm{VO}_{2}\right)$, relotive oxygen consumption $\left(M \mathrm{VO}_{2}\right)$, minute volume $\left(\mathrm{V}_{\mathrm{E}}\right)$, volume of corbon dioxide produced $\left(\mathrm{VCO}_{2}\right)$, respiratory quotient (RQ), breathing frequency (BF) and froctions of expired oxygen $\left(\mathrm{FeO}_{2}\right)$, and corton dioxide( $\left(\mathrm{FeCO}_{2}\right)$. Prior to 
the rowing ergometry tests, the gas anolyzers were colibrated with a known quantity of gas $\left(\% \mathrm{CO}_{2}=3.81, \% \mathrm{O}_{2}=15.92\right.$ ) determined vio the Scholander technique (Scholender, 1947). Periodic gos samples were tested between subjects to check the stability of the colibrotion.

Testing conditions et the Human Performance Loboratory were moderate with an averoge (+ - standard deviation) temperoture of $22.1+-.8$ C and humidity $49 \%+-4 \%$. All gos volumes were converted to standard temperoture, pressure, and dryness ( O C, $760 \mathrm{mmHg}, 0 \%$ humidity) for metabolic colculation (Katch et al., 1981).

Actual Performence

Rowing performance was meosured os the elapsed time to complete two 3.5 mile rowing tests performed on the Concept II rowing ergometer. Subjects performed tests individually in the laboratory setting while a coxswoin provided verbal stroke cadence and laborotory assistants collected test doto.

\section{Statisticol Analysis}

All data that were collected in the study were key punched and processed of the Academic Computer Center ot the University of Rhode Island. Paired T-tests were performed between the same testing variables on different testing days. The formulo for the dependent $T$-test is

where

$$
t=\frac{\bar{D}}{\frac{\sqrt{\Sigma D^{2}-\frac{(\Sigma D)^{2}}{N}}}{N(N \cdot 1)}}
$$

$t=$ the $t$-value for dependent means

$D=$ the difference between the poired scores

$\bar{D}=$ the mean of the differences

- $\Sigma D^{2}=$ the sum of the squored difference scores

$N=$ the number of poirs 
Means and standard deviations were also colculated to determine scores ronkings.

\section{YARIABLES TESTED}

The following variables were tested:

\section{Physiological Voriables}

- Maxímal oxygen consumption (V02 max)

(1iters . $\min -1$ )

- Maximal oxygen consumption (ml . kg

$. \min -1)$

- Ventilatory equivelent

- Minute volume

- Respiratory Quotíent

- Breathing frequency

- Heart Rote

\section{Performance Voriobles}

- Performance Time (min:sec)

- Stroke Rate 
CHAPTER IV

\section{RESULTS AND OISCUSSION}

\section{Descriptive Statistics}

Physiological Characteristics

The mean physical characteristics of subjects are presented in Table 1. When compared to 12 candidates for the 1983 United States Men's Lightweight Rowing Team (Mohler et al., 1984), subjects in the present study tended to be slightly shorter and heovier, with Mahler et al. (1983) reporting an average height of $183+-3 \mathrm{~cm}$ and weight of $72.2+-1.4 \mathrm{~kg}$. The percentage of body fot of the subjects in this study wos higher (11.26\%) when compered to the 7 to 8 percent reported by Hogermen et al., (1984) and the 8.5 percent reported by Burke (1980) for lightweight oorsmen. Subjects tested in the present study were tested in the off season and were not in peak condition. This may explain some of the difference between group scores in percentoge of body fot. Hogerman and Staron (1983) found elite oarsmen to have quite extreme seasonel variations across all physiological variables.

\section{Testing Times}

Toble 2 reports the meen group scores of total time taken to complete the "all-out" and pacing exercise tests. The group averoge for the completion of the 3.5 mile rowing ergometry test employing the all-out strategy wos $6^{\circ} 19.6^{\circ}+-6.13^{\circ}$. The group overage for total time when subjects employed the pocing strategy was $6^{\prime \prime} 20.3^{\prime \prime}+-8.31^{\prime \prime}$. As these times 


\section{TABLE 1}

PHYSICAL CHARACTERISTICS

AGE

21

21

21

20

21

25

21

22

19

19

MEAN

S.D.
21

1.7 HEIGHT(CM)

177.80

185.42

180.34

182.88

180.34

179.07

175.26

180.34

175.26

171.45

178.82

4.10

13.97
WEIGHT(CM)

79.55

75.23

71.82

73.41

75.68

78.86

71.48

76.36

66.48

69.09

73.80

4.20

13.07
\& BODYFAT

14.80

11.31

9.86

10.99

10.40

7.90

13.50

9.97

8.21

15.70

11.26

2.60

7.80 


\section{TABLE 2}

GROUP MEAN STROKE RATES AND PHYSIOLOGICAL VALUES OVER COMPLETE AO AND P PROTOCOLS

AO Sd+- $P$ Sd+- $P$

\begin{tabular}{|c|c|c|c|c|c|}
\hline STROKE RATE (S/MIN) & 30.6 & 1.17 & 31.7 & .949 & .01 \\
\hline HEART RATE (BEATS/MIN). & 177.6 & 7.70 & 173.0 & 6.65 & .05 \\
\hline M2 (L/MIN) & 4.29 & .242 & 4.05 & .315 & .01 \\
\hline 12 (ML/KG/MIN) & 58.63 & 3.70 & 55.01 & 3.69 & .01 \\
\hline TIM & 379.6 & 8.13 & 380.3 & 8.31 & NS \\
\hline
\end{tabular}


report, a difference of only . 7 was found between the group overoges for the two protocols, demonstrating near identical performance times. These times are less than the 6' $36^{\prime \prime}$ reported as the medion times obtained by the FISA regattos from 1974 to 1962 in the men's open class.

\section{Stroke Rate}

Figure 1 shows the group mean stroke rotes across each 30 seconds of the two testing protocols. Stroke rates for subjects performing the AO protocol were considerably higher during the first 30 seconds when compared to the rotes over the first 30 seconds of the $P$ test. Following similar rates recorded ot the 60 second mark, subjects achieved and maintoined higher stroke rotes using the $P$ protocol for the remainder of the test. Table 3 shows the group mean values of subjects' stroke rates across each 30 seconds of the two testing protocals along with the averoge stroke rates across all 30 second time periods. Also shown in Table 3 are probability values resulting from dependent T-tests applied to the two exercise tests.

During the first 30 seconds of each test, a significant difference was seen in the overage stroke rates subjects attained performing the two lesting protocols. Subjects overoged 36.7 strokes per minute (SPM) while performing the "all-out" test compared to 32.1 SPM during the first 30 seconds of the $P$ test. At the 60 second mark, little difference was seen in the overoge stroke rates subjects achieved, with an overoge of $30.3 \mathrm{SPM}$ achieved during the AO test and 31.2 SPM during the $P$ test. This 60 second time period is where the cross over in protocols was designed, with subjects being cooxed to reduce their stroke rotes from 36 SPM to 30 SPM 


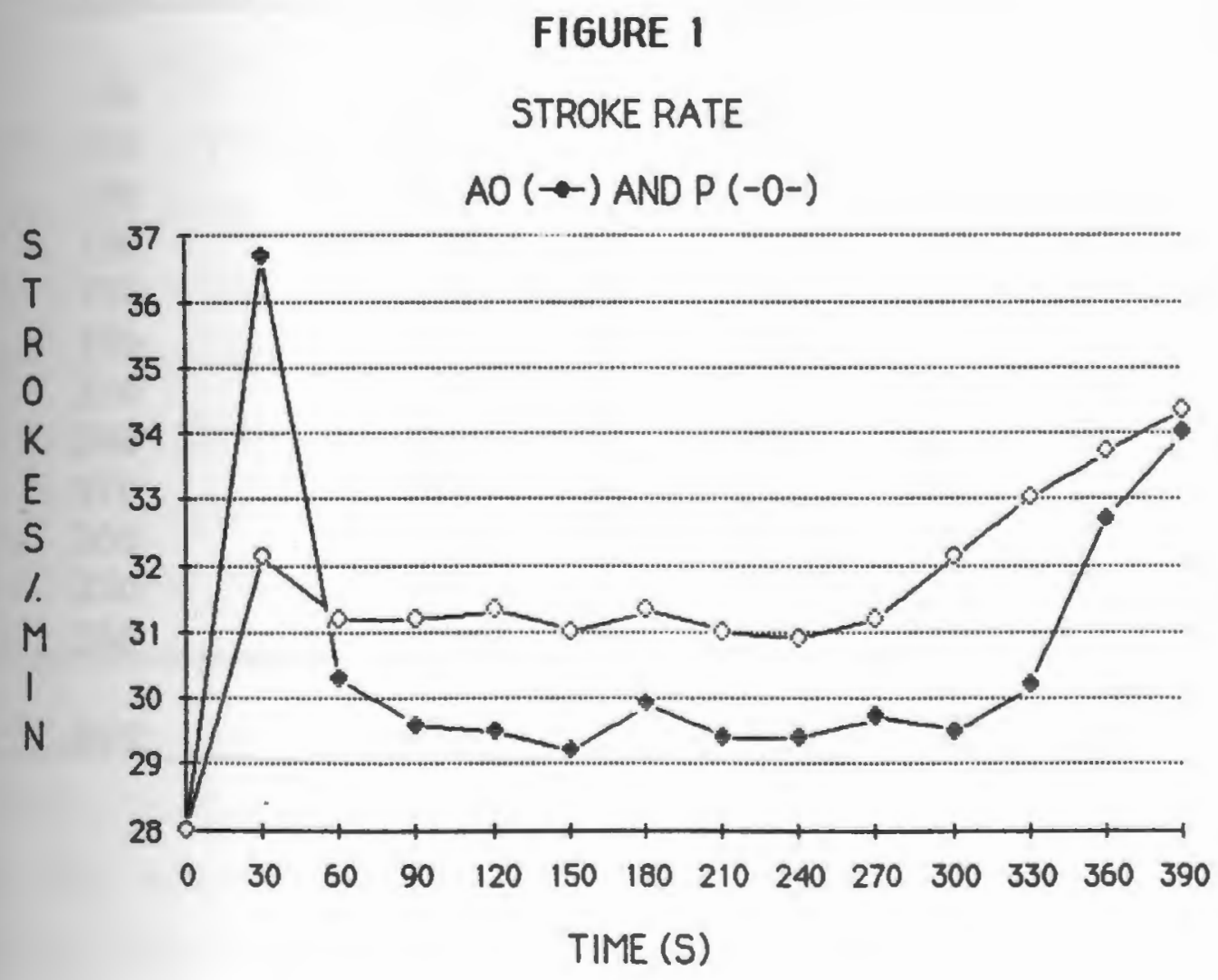


TABLE 3

STROKE RATE (strokes $\cdot \min ^{-1}$ )

IIME (sec) ALL-DII S.D. PACING S.D. O

\begin{tabular}{rrrrrr}
30 & 36.7 & 1.78 & 32.1 & 1.20 & .01 \\
60 & 30.3 & 2.11 & 31.2 & .79 & ns \\
90 & 29.6 & 1.09 & 31.2 & .73 & .01 \\
120 & 29.5 & 1.18 & 31.3 & .68 & .01 \\
150 & 29.2 & 1.23 & 31.0 & 1.05 & .01 \\
180 & 29.9 & 1.60 & 31.3 & .82 & .01 \\
210 & 29.4 & .84 & 31.0 & .82 & .01 \\
240 & 29.4 & 1.08 & 30.9 & 1.10 & .01 \\
270 & 29.7 & 1.34 & 31.2 & 1.14 & .01 \\
300 & 29.5 & 1.35 & 32.1 & 1.29 & .01 \\
330 & 30.2 & 1.75 & 33.0 & 1.56 & .01 \\
3.00 & 32.8 & 1.48 & 33.7 & 1.00 & ns \\
\hline
\end{tabular}

N6 $\quad 30.6+-1.17 \quad 31.7+95 \quad .21$ 
in the AO protocol and from 32 to 31 SPM in the P protocol for the body of the test. After this cross over, subjects performing the P protocol achieved Agnificantly higher stroke rates over each 30 second mark for the duration of the $P$ test until the 360 second mark, where significance at the .05 level was barely missed. These differences were designed within the protocols prior to testing and show that distinct protocol differences were achieved. During the last .5 mile of each protocol, or approximately the last minute of the test, subjects were coaxed into their final sprint in which they were to perform at maximal effort until the $\mathbf{3 . 5}$ mile mark was achieved. During this time period, subjects performing the P test were able to increose their stroke rates faster and maintain this increased rate longer when compared to their AO test peformance. Over the entire test, subjects averaged a greater stroke rote during the $\mathrm{P}$ test when compored to the $\mathrm{AO}$ test.

In summary, with the exception of the 60 second stroke rate scores, a significant difference at the .01 level was seen between all 30 second mean scores of the AO test when compared to the P test. Subjects ottained - higher stroke during the first 30 seconds of the AO test, o similar stroke rote at the $\mathbf{6 0}$ second mark, and a significantly higher rate during the last $\mathbf{5}$ minutes of the P protocol. Subjects were oble to maintain this higher stroke rate over the entire $P$ test. Distinct protocol differences were designed and achieved within each of the two testing protocols.

\section{Heart Rate}

Heart rate (HR) data were only collected on nine subjects. Figure 2 shows the group mean heart rote values across eech 30 seconds of the two testing protocols. Heart rates recorded during the $\mathrm{AO}$ protocol were higher 
FIGURE 2

HEART RATE

AO ( - ) AND P (-0-)

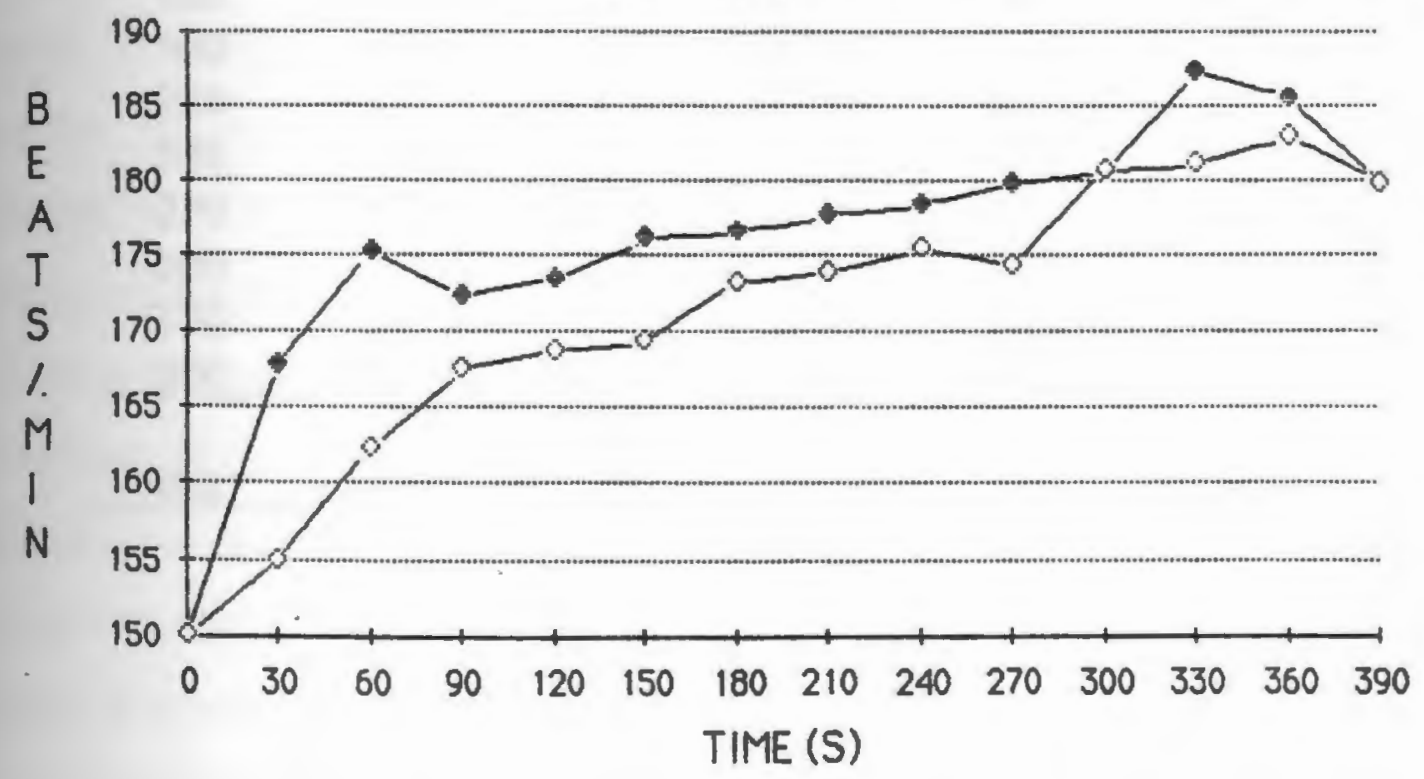


TABLE 4

HEART RATE (beots $-\min ^{-1}$ )

\begin{tabular}{|c|c|c|c|c|c|}
\hline 2 & ALL-DUT & S.D. & PACING & S.D. & e \\
\hline 30 & 167.8 & 14.01 & 156.0 & 12.00 & .05 \\
\hline 60 & 175.2 & 12.27 & 164.8 & 8.01 & .05 \\
\hline 90 & 172.2 & 9.19 & 168.9 & 6.07 & .05 \\
\hline 120 & 173.6 & 8.02 & 170.6 & 5.77 & ns \\
\hline 150 & 176.2 & 8.09 & 168.6 & 8.62 & .01 \\
\hline 180 & 176.7 & 9.22 & 173.2 & 8.50 & ns \\
\hline 210 & 177.8 & 7.61 & 175.2 & 6.78 & ns \\
\hline 240 & 178.3 & 8.32 & 176.4 & 5.92 & ns \\
\hline 270 & 179.9 & 9.20 & 174.4 & 8.13 & .01 \\
\hline 300 & 180.8 & 9.62 & 181.1 & 8.78 & ns \\
\hline 330 & 187.2 & 10.01 & 182.1 & 9.29 & ns \\
\hline 360 & 185.4 & 8.43 & 184.1 & 11.42 & ns \\
\hline
\end{tabular}


at end of the first 30 seconds and remoined higher over the entire $A 0$ test. Table 4 shows the group mean values of subjects' heart rate across each 30 seconds of the two testing protocols and overoge heart rate values across all 30 second tíme periods. Also shown in Table 4 ore probebility values between the subjects' performance on the two exercise tests.

The first 30 second scores show o significontly higher HR response during the $\mathrm{AO}$ test with subjects overaging 167.8 beots $\cdot \min ^{-1}$ during the AO protocol and 156.0 beats $\cdot \mathrm{min}^{-1}$ during the P protocol. This is seen as the response to the significently higher stroke rotes reported during the first 30 seconds of the AO test. HR volues remained higher throughout the entire $A O$ test, reaching significance ot the 150 second and 270 second marks. No significent differences were seen in HR's between the tests during the last 2 minutes. Group mean HR values across all 30 second scores over the entire test were significontly higher $(p<.05)$ in the AO test. These differences were seen despite the significontly lower stroke rotes recorded during the AO protocol. When compered to the "all-out" and progressive incremental protocols performed by 12 members of the 1983 United Stotes Men's Lightweight Rowing Team (Mohler et ol., 1984), the heart rote responses of the subjects used in this study were very similer. During his AO test, Mohler et ol. reported o meen heort rote volue of 177 beats - minute ${ }^{-1}+-7$ beots $\cdot$ minute ${ }^{-1}$ wos ochieved during the first minute which gradually increased to $183+-6 \mathrm{~b} \cdot \mathrm{min}^{-1}$ by the sixth minute. Subjects in the present study responded similerly ot the 1 minute mork with on overoge of 175.2 during the $A 0$ test which remoined slightly higher with on overoge of 185.4 ot the sixth minute.

In summory, the overage HR recorded throughout the 3.5 mile $A 0$ protocol was significantly higher than the heort rate values recorded for the 
$P$ protocol. Mean group HR's were significently higher throughout the first 90 seconds in the $A 0$ testing protocol and remained higher throughout the entire test. Averoges across all 30 second scores for the entire test were also significantly higher in the $\mathrm{AO}$ test despite a significantly lower stroke rote performed during the $\mathrm{AO}$ test.

\section{Absolute Oxygen Consumption}

Figure 3 shows the mean absolute oxygen consumption (VOL) for all ten subjects across each 30 seconds of the two testing protocols. Subjects consumed more oxygen over the first 30 seconds of the AO protocol and absolute oxygen consumption remained greater during the remainder of the AO test. Table 5 reports the group mean values of subject's absolute oxygen consumption across each 30 seconds of both testing protocols. Also reported in Table 5 ore the probobility values between the subject's performance on the two exercise tests.

The first 30 second scores show a significantly higher absolute oxygen consumption by subjects performing the AO protocol with mean values of $1.74 \mathrm{l} / \mathrm{min}$ and $1.50 \mathrm{l} / \mathrm{min}$ for the $A 0$ and $P$ protocols, respectively. Absolute oxygen consumption values also remained higher throughout the duration of the A0 protocol with values showing significance ot the 60,90, 120, 240, and 360 second marks. The significantly higher oxygen consumption throughout the first two minutes of the test is seen os a response to the significontly higher stroke rates performed during the first 30 seconds of the $A 0$ test.

In summery, the totol oxygen cost to complete the A0 test wos significontly higher when compared to the $P$ test. This oxygen consumption relates directly to energy production over the individual 30 second seg- 
FIGURE 3

ABSOLUTE OXYGEN CONSUMPTION

\section{AO (- -$)$ AND P (-0 )}

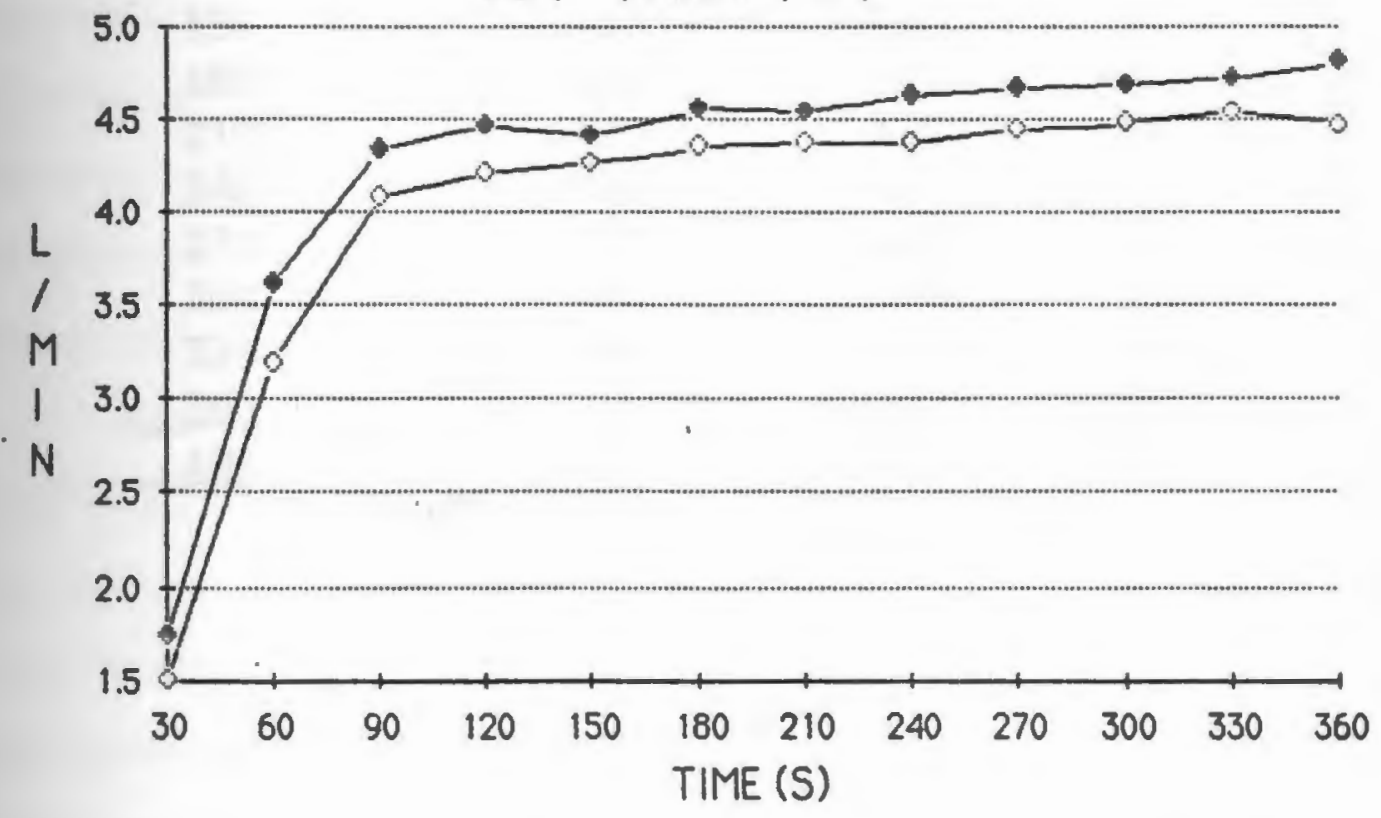


TABLE 5

ABSOLUTE OXYGEN CONSUMPTION (LITERS $\cdot$ MIN $^{-1}$ )

TIME (SEC)

\begin{tabular}{rlll}
30 & 1.74 & 1.50 & .01 \\
60 & 3.62 & 3.20 & .01 \\
90 & 4.33 & 4.07 & .05 \\
120 & 4.47 & 4.20 & .01 \\
150 & 4.41 & 4.26 & $\mathrm{~ns}$ \\
180 & 4.55 & 4.35 & $\mathrm{~ns}$ \\
210 & 4.53 & 4.37 & $\mathrm{~ns}$ \\
240 & 4.63 & 4.37 & .01 \\
270 & 4.67 & 4.45 & $\mathrm{~ns}$ \\
300 & 4.69 & 4.48 & $\mathrm{~ns}$ \\
330 & 4.73 & 4.54 & $\mathrm{~ns}$ \\
360 & 4.81 & 4.47 & .05 \\
\hline AVG & 4.29 & 4.05 & .05 \\
\hline
\end{tabular}


ments and for the entire exercise test. Therefore, where volues of oxygen consumption are significontly higher, o significantly greater energy cost can be attributed to a given segment and to an entire exercise test. With the significantly higher absolute oxygen consumption reported for the AO protocol, this greoter energy cost is seen.

\section{Relative Oxygen Consumption}

Figure 4 shows mean relative oxygen consumption (MV02) across each 30 second period for both exercise protocols. The subjects relative oxygen consumption was greater at the 30 second mark in the $\mathrm{AO}$ protocol and remained higher throughout the duration of the test. Table 6 reports the group mean relative oxygen consumption values across each 30 seconds of both the AO and P protocols. Also shown in Table 6 are the significant differences between the subject's performance during the two tests.

Subjects consumed significantly more oxygen relative to body weight during the first 30 seconds of the $A O$ protocol with o mean value of $23.75 \mathrm{ml} / \mathrm{kg} / \mathrm{min}$ compared to $20.29 \mathrm{mi} / \mathrm{kg} / \mathrm{min}$ during the first 30 seconds of the P protocol. AO test volues remoined significantly higher through the first two minutes and at the $180^{\circ}, 240^{\circ}$, and $360^{\circ}$ marks. Mean relative oxygen consumption over the entire testing protocols was also significantly higher in the $A O$ test.

In summary, when oxygen consumption was assessed in relation to subjects' body weight, subjects consumed a greoter amount of oxygen, on overoge, in the AO test when compored to the P test. Subjects mean relative oxygen consumption wos significontly greater during the first two minutes, between the $150^{\circ}$ and $180^{\circ}$ marks, between the $210^{\circ}$ and $240^{\circ}$ marks, 
FIGURE 4

RELATIVE OXYGEN CONSUMPTION

$$
\text { AO (- -) AND P (-0-) }
$$

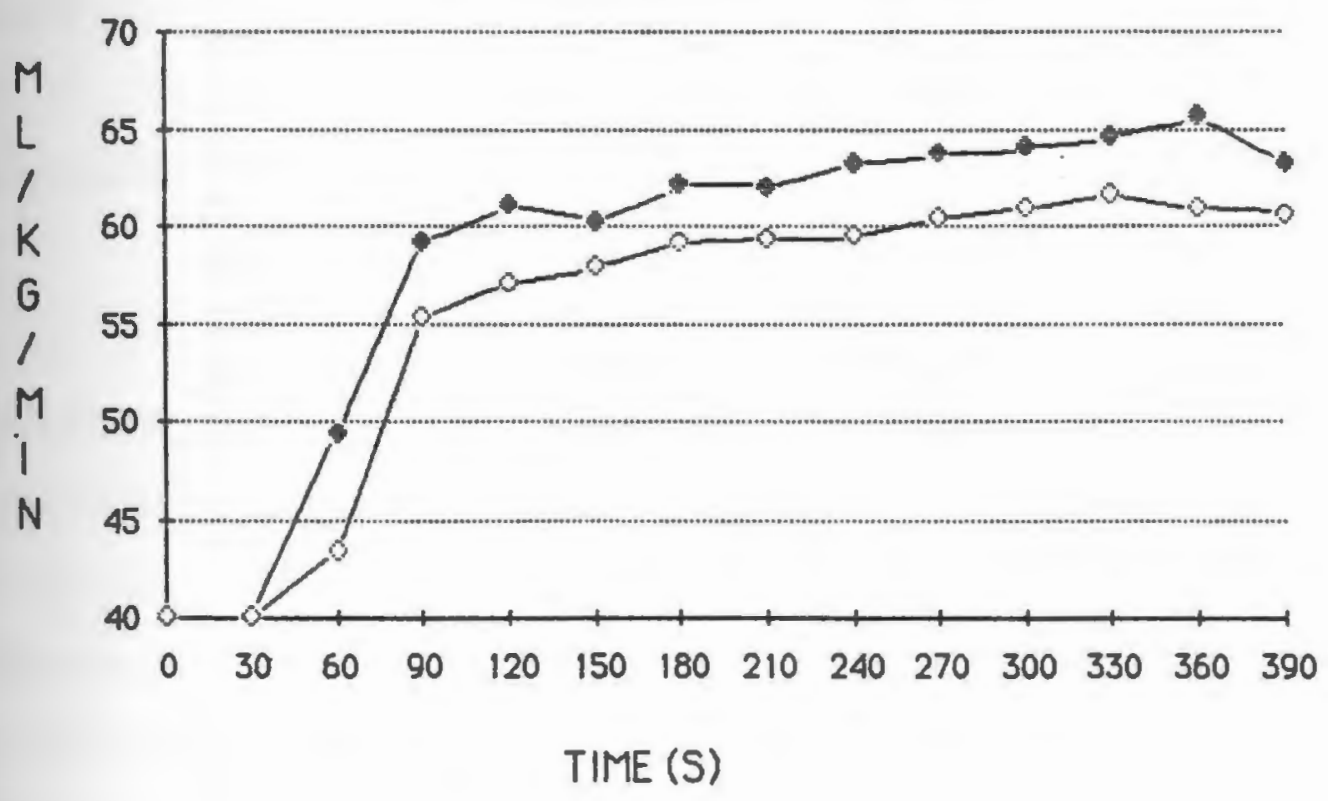


TABLE 6

RELATIYE OXYGEN CONSUMPTION (ML/KG/MIN)

\begin{tabular}{clll} 
IIME (SEC) & ALL-OUI & PACING & O \\
\hline 30 & 23.73 & 20.29 & .01 \\
60 & 49.31 & 43.46 & .01 \\
90 & 59.20 & 55.33 & .01 \\
120 & 61.12 & 57.15 & .01 \\
150 & 60.34 & 57.97 & $\mathrm{~ns}$ \\
180 & 62.10 & 59.22 & .01 \\
210 & 61.97 & 59.40 & $\mathrm{~ns}$ \\
240 & 63.26 & 59.50 & .01 \\
270 & & & \\
300 & 64.10 & 60.94 & $\mathrm{~ns}$ \\
330 & 64.60 & 61.69 & $\mathrm{~ns}$ \\
360 & 65.65 & 60.91 & 05 \\
AYY & 58.63 & 55.01 & 01
\end{tabular}


and between the $270^{\circ}$ and $300^{\circ}$ marks of the $\mathrm{AO}$ test. This oxygen consumption relotes directly to energy costs during individual 30 second segments, and totol energy costs of the entire exercise test. Thus, more energy wos utilized in completing the $A D$ protocol then was used in the $P$ protocol.

\section{Test of Hypothesis}

Hypothesis 1

Subjects will ochieve o foster time while rowing 3.5 miles using the $\mathrm{P}$ protocol as opposed to the traditional $\mathrm{AO}$ protocol.

Table 6 reports the mean group scores of total time taken to complete both the AO and P exercise tests. The group overage for the completion of the 3.5 mile rowing ergometry test employing the $A 0$ strotegy was $6^{\prime} 19.6^{\prime \prime}+-6.13^{\prime \prime}$. The group overage for totol time when subjects employed the P strotegy wos $6^{\circ} 20.3^{\prime \prime}+-6.31^{\prime \prime}$. Though employing quite different testing strategies over the duration of the two testing protocols, the difference in totol times taken to complete the 3.5 mile protocols were not significontly different. Therefore, hypothesis I was rejected.

\section{Hypothesis 11}

Mean heart rotes will be higher in subjects performing the $\mathbf{A O}$ protocol when compored to the P protocol. 
Figure 2 and table 3 report the heart rate values for both protocols across same time periods along with total test overages during the two testing sessions. Subjects attained o higher rate immediately ot the start of the $A D$ test and maintained this higher rate throughout the duration of the AO test. The overoge of these scores ocross the entire tests wos significantly higher for the $A D$ test when compared to the $P$ test and, therefore, hypothesis II was accepted.

Hypothesis III

The average energy cost of the pacing protocol will be less then the $A O$ protocol as measured by mean absolute and relative axygen consumption.

Figures 3 and 4 along with tables 5 and 6 show obsolute and relative oxygen consumption values across same time periods and total test overages. Consumption in both absolute and relative terms was higher at the initial 30 second calculation of the $A O$ protocol and remained higher for the duration of the test when compared to the $P$ protocol. Average consumption for the entire tests were also significantly higher in the AO test when expressed in both obsolute and relative terms. Estimates of caloric costs determined by the methods described by McArdle (1981) require multiplying each liter of oxygen consumed by a constant of 4.82 kilocolories to estimate total energy costs of a given exercise. The understanding of this calculation allows us to conclude that a significantly greater amount of energy was consumed during the AO test. Therefore hypothesis III wos accepted. 
Practical Implications

The purpose of the present study wos to determine if the pocing strategy employed in the majority of aerobically based endurance events could be applied to the sport of race rowing where o unique pattern of racing strategy has evolved over the years. This strategy is often referred to as the "all-out" pace. Extremely high energy expenditures and elevated oxygen costs are demanded over the initial 30 to $\mathbf{4 5}$ seconds of the race followed by - slower steady rote performance level for the middle 4 to 5 minutes of the race, and finally an anoerobic sprint over the last 45 to 60 seconds of the race. The pacing strategies used in the mojority of endurance events, which typically include a steady aerobic worklood over the majority of the race with on anoerobically bosed sprint over the final 45 to 60 seconds of the race wos what the $\mathrm{P}$ protocol in the present study simulated. Significant differences in stroke rates and selected physiologic responses were found between the two protocols. However, when considering performance over the 3.5 mile rowing ergometer tests, little difference wos reported in times to complete the two exercise tests.

Absolute and relative oxygen consumption values were significantly higher over the first two minutes and on average for the entire $A O$ test, which clearly indicate a higher metabolic cost for "all-out" performance. Subjects expended significently more energy during the AO test without any advantoge in actual performance. Conversely, the metobolic dato suggests that the oorsmen "conserved" significantly more energy during the P test without any advantage in actual performence. At a glance, this finding seems contradictory. However, it should be noted that all subjects were 
coaxed in the identical manner during the last minute of each test when they were instructed "oll-out". During this time, the subjects performing the $P$ test were able to increase their stroke rate more quickly as well os maintain higher stroke rotes throughout the completion of the test.

From these observations it may be implied that the AO test or troditional approach did not elicit of fovoroble response from the subjects in that its start required too great an energy demand from which subjects never appeared to recover. This was demonstrated in the difficulty to increase and maintain a greater stroke rate over the last minute of the race. The strategy employed in the P protocol allowed the subjects to increase their stroke rates and maintain them until the $\mathbf{3 . 5}$ mile mark was reached. These data suggests that the stroke rates employed in the $P$ protocol may not have been demanding enough to push each subject to his maximal performance. This "settled" rate of the $P$ test may not have optimized the conditioning of these well trained athletes, leaving them with a greater energy reserve than necessary for the middle and final stages of the 3.5 mile row. A strategy employing the $P$ tests make-up of o slightly higher "settled" stroke rate through the body of the test would allow for slightly faster stroke rates without the drastic changes employed in the traditional strotegy.

The practical question facing researchers and cooches alike lies in how one can determine the proper pacing strotegy to allow for optimal increases in the oxygen transport system without any of fect of anaerobic metabolism. In many endurance events the anaerobic threshold is used to determine this point. However, due to the significant workload placed on oarsmen of the beginning of o race to get the rowing shell in motion, an anaerobic response 
is inevitable in the first 1 to 2 minutes.

Recommendotions for Future Research

Race rowing, os in all other competitive rocing events, poses the challenge to athletes and cooches alike to develop o racing strategy that will elicit optimal performance in the event of their choice. To this point, tradition, more than scientific knowledge and experiments has dictated the unique strotegy employed by most elite oarsmen and rowing teams. The pattern of beginning races at extremely high energy expenditures along with - marked onaerobic response has remained the sport's trodemark. The present study presents metabolic information which questions such on approach. Though subjects were unaccustomed to the $P$ protocol in the present study and expended significantly less energy during this test, times for the $P$ test were nearly identical to those achieved during the $A O$ test. Conversely, subjects performing the A0 protocol, o racing strategy that was fomilar and procticed, had o metabolic cost which was significontly greater without any improvement in actual performance. Of interest to both the othlete and coach alike would be a similar study which employed a period of experimenting with stroke rates in on effort to find the optimal rate for the $P$ test. This type of test would allow for the subjects to become fomilar with o steadier roce pace than they traditionally follow and moy result in subjects "finishing strong" os opposed to "holding on" during the final minute of a rowing race.

A second study should include the training of oorsmen in the foshion presented by the present studies $P$ test. By keeping the pocing strotegy 
relatively consistent and increosing the intensity ocross on entire troining session or competition as subjects become more fit and not any porticular portion of the race over the other portions, on oorsman would approoch his troining and performance in a more troditional and phsiologically sound opproach.

Conclusions

1) A significontly higher stroke rate moy be mointoined during o 3.5 mile rowing ergometry test when using o pacing strotegy os opposed to on "oll-out" strotegy.

2) Heart rotes responses are significantly higher during on "all-out" rowing test of 3.5 miles when compored to a rowing protocol employing o pacing strotegy.

3) Energy requirements os estimated from oxygen consumption ore significantly higher during a 3.5 mile row employing an "all-out" strategy when compared to a pacing strategy. 


\section{APPENDIXA}

HYDROSTATIC WEIGHING FORMULAS

Subjects percentage of body fot wos estimated using the following formulas decribed in McArdle, W.D., Katch, F.I., and Katch, Y.L. (1981) Exercise Physiology: Energy, Nutrition. and Human Performance, Philedelphia, Leo and Febiger.

Archimedes' Principle allows us to determine on objects density when submerged in water. This formula is expressed:

$$
D b=M a \times D w /(M a-M w-R V \times D w)
$$

Where $M a=$ Body weight in kilograms

Dw $=$ Water temperature correction

$M w=$ Net underwoter weight in kilograms

RV = Residual lung volume in liters

Once the density of a body is known, a simplified Sirt equation is used. The eqation is obtained by substituting the known densities of lean and fat reight, $1.10 \mathrm{~g} \times \mathrm{cc}-1$ and $.90 \mathrm{~g} \times \mathrm{cc}-1$, repectively into the following equation

$$
D=\frac{F+L}{(F / f)+(L / 1)}
$$

By rearrenging the terms, the proportional contribution of $F$ (fat percentage) becomes:

$$
F=\frac{1}{D} \times \frac{[x]}{(1-f)}-\frac{1}{1-f}
$$

It's derivation by Berkeley scientist Dr. William Siri is:

$$
\text { Percent fat }=\frac{495}{\text { Density }}-450
$$


Ag̣nevik, G., Korlsson, J. et ol. (1967) Energy demonds during running. Second Internotional Seminar of Ergometry, W. Berlin, p281.

Astrond, P. O. and Rodohl, K.(1977) Texthook of Hork Physiology, 2nd ed. (McGrow-Hill, New York).

Corey, P., Stenslend, M., and Hortley, L. (1974) Comporison of oxygen uptake during maximal work on the treadmill ond rowing ergometer. Medicine and Science in Soort 6: 101-103.

Celentano, F., Cortilli, G., DiPrompero, P. E., and Cerotelli, P. (1974) Mechonical aspects of rowing. Joumol of Apolied Physiology, 36: 642-647.

Clerk, J. M., Hogerman, F. C., and Gelfand, R. (1983) Breathing potterns during maximal and submoximal exercise in elite oorsmen. Jourmal of Apolied Physiology, 55: 440-446.

Clarkson, P. M., Johnson, J., Melchiondo, A., and Groves, J. (1983) Isokinectic strength, fatigue, ond fiber type in elite oorswomen. (Abstract). Medicine and Science in Sport and Exercise, 15: 170.

Connors, M. C. (1974) An energetic onolysis of rowing. Doctoral Disertation (Ohio University, Athens, Ohio).

Cunninghem, D. A., Goode, P. B., and Critz, J. B. (1975) Cordiorespiratory response to exercise on o rowing and bicycle ergometer. Medicine and science in Soort, 7: 37-43.

de Goroy, A. L., Levine, L. and Corter, J. E. L. Genetic and Anthronological Studies of Olympic Athletes (Acodemic Press, New York, 1974).

DiPrompero, P.E., Cortili, G., Celentano, F. and Cerretelli, P. (1971) Physiological aspects of rowing. Journal of Apolied Physiology, 31: 853-857.

DiPrampero, P. E., Pinero Limas, F., and Sassi, G. (1970) Maximal muscular power (aerobic and anerobic) in 116 athletes performing at XIX Diympic Gomes in Mexico. Ergonomics, 13: 665-674. 
FISA Cooches Conference Report; in Proceedings of the FISA Cooches Conference, Rome, Itoly, Oct. 1980 (Albrecht Philler Verlog, Minden 1983).

Hogermon, F. C. (May, 1969) Respiratory distress among oorsmen during competition ot the 1960 Summer Olympic Games. Medical Tribune, p. 12.

Hagerman, F. C. (1974) Metobolic responses of women rowers during ergometric rowing. (obstrct). Medicine ond Science in Sperts, 6: 07.

Hegerman, F. C. (1975) Teamwork in the hardest pull in sports. Physicion and Sportsmedicine, 3: 39-44.

Hagermen, F. C., Addington, W. W., and Goensler, E. A. (1972) A comparison of selected physiological voriobles among outstanding competitive oorsmen. Joumol of Soorts Medicine and Physical Fitness, 12:12-22.

Hagerman, F. C., Addington, W. W., and Goensler, E. A. (1975b) Severe steady state exercise at sea level and altitude in Olympic oorsmen. Medicine and Science in Sports, 7: 275-279.

Hagermon, F. C., Connors, M. C., Goult, J. A.,Hagerman, G. R., and Polinski, $W$. J. (1978) Energy expenditure during simulated rowing. Journal of Apolied Physiology, 45: 87-93.

Hagerman, F. C.,Hagerman, G. R., and Mickelson, T. C. (1979) Physiological profiles of elite rowers. Physicion ond Sportsmedicine, 7(7): 74-61.

Hagerman, F. C. and Howie, G. A. (1971) Use of certain physiological veriables in the selection of the 1967 New Zeoland crew. Research Querterly of the Americon Assiciation of Health and Physical Educotion, 42: 264-273.

Hagerman, F. C. and Lee, W. D. (1971) Meesurement of oxygen consumption, heort rote, and work output during rowing. Medicine and Scjence in Sports. 3: $155-160$.

Hogerman, F. C. ond Mansfield, M. C. (1984) A comporison of energy cost and mechanical efficiency at identicle power outputs between a mechanical veriable-resistance rowing ergometer and a mechenical fixed resistance bicycle ergometer. (Abstract). Medicine and Science in Sports and Exercise $.16: 125$. 
Hagerman, F. C., Mckirnan, M. D., and Pompel, J. A. (19750) Maximal oxygen consumption of conditioned and unconditioned oarsmen. Journal of Snorts Medicine, 15: 43-48.

Hegermen, F. C. and Mickleson, T. C. (1981) A tesk specificity comporison of oneerobic thresholds among competitive oarsmen. (Abstract). Medicine and Science in Sports and Exercise, 13: 17-20.

Hegermon, F. C. and Staron, R. S. (1983) Seosonal yoriations omong phystologicol voriobles in elite oarsmen. Conodion Joumal of Anolied Sports Science, 8: 143-148.

Hagermon, G. R. (1976) Metabolic evoluation of international caliber lightweight oersmen. Doctoral Dissertation (Ohio University, Columbus, Ohio).

Homby, E. J. and Thomos, V. (1969) Comparison of rowing and cycling work copocity tests using heart rate os the perameter. Jourmal of Physiology, 203: BOP-61P.

Harrison, J. Y. (1967) A constant torque-brake for use in bicycle and other ergometers. Journal of Applifed Physiology, 23: 482-483.

Harrison, J. Y. (1970) Moximizing humen power output byy suitable selection of motion cycle and lood. Humen Factors, 12: 315-329.

Hoy, J. G. (1960) Rowing: on analysis of the New Zeolond Olympic selection tests. New Zealond Journal of Health Physical Educotion and Recreation, 1: 83-90.

Hebblenick, M., Ross, W. D., Carter, J. E. L., and Boems, J (1980) Anthropometric charocteristics of femole Olympic rowers. Cenodion Journol of Apllied Sports Sciences, 5: 255-262.

Henderson, J. Y. and Hoggard, H. W. (1924) The maximum of humen power and it's fuel.Americen Journal of Physiology, 72: 264-288.

Ishiko, T. (1967) Aerobic capacity and external criteria of performance. Conodian Medical Associotion Journal, 26: 746-749.

Ishiko, T. (1968) Applicotions of telemetry to sports activities; in Wortenweiler et al. (Eds) Biomechanics, I, pp 138-146 (Karger, Bosel). 
Jackson, R. C. and Secher, N. (1973) The metabolic cost of rowing and physiological characteristics of world closs oorsmen. (Abstroct) Medicine and Science in Soorts, 5: 65.

Jackson, R. C. and Secher, N. H. (1976) The aerobic demands of rowing in two Olympic rowers. Medicine in Science and Snorts, 8: 168-170.

Larsson, L. and Forsberg, A. (1980) Morphological muscle characteristics in rowers. Conodion Journel of Apolied Sports Sciences, 5: 239-244.

Liljestrand, G. and Lindherd, J. (1920) Zur Physiologie des Ruderns. Skandinavisches Archiv fur Physiologie, 39: 215-235.

McArdle, W. D., Katch, F. I., Kotch, V. L. (1981) Exercise Physiology - Energy, Nutrition, and Humen Performence, Philodelphia, Leo and Febiger.

Mohler, D. A. (1984) Comparisons of six minute "oll-out" and incremental exercise tests in elite oorsmen. Medicine ond Science in Soorts and Exercise. Submitted for publication.

Mahler, D. A., Anderson, D. C., Parker, H. W., Mitchell, W. S., and Hegermon, F. C. (1983) Physiologic comparison of rowing performance between notional and collegiate women rowers. (Astract) Medicine and Science in Soort ond Exercise, 15: 157.

Margario, R., Cerretelli, P., DiPrompero, P. E., Mossari, C., and Torelli, G. (1963) Kinetics and mechanisms of oxygen debt contraction in mon. Journel of Apolied Physiology, 19: 623-628.

Mergoria, R., Cerretelli, P. and Mangili, F. (1964) Balance and kinetics of onoerobic energy releose during strenuous energy releose in mon. Journol of Aoplied Physiology, 19: 623-628.

Margario, R., Edwords, H. T., and Dill, D. B. (1963) The possible mechonisms of contracting and paying the oxygen debt and the role of lactic acid in musculer contraction. American Journal of Physiology, 106: 689-715.

Mellerowicz, H., and Honsen, G. (1965) Suerstoff Kapazitat und andere spiro-ergometrische maximal werte der Ruder-Olympiosieger im viser mit st. vom Berliner Ruderclub. Sportartz und Sportmedizin, 5: 188. 
Mickleson, T. C., and Hogerman, F. C. (1982) Anoerobic threshold meosurements of elite oorsmen. Medicine ond Science in Soorts and Exercise 14: 440-444.

Niu, H., Ito, K., Tokagi, K., and Ito, M. (1966) A study of the developement of cordio-respirotory function of the oorsmen; in Koto (Ed.) Proceedings of Internotional Congress of Sports Sciences, Tokyo, October, 1964, pp. 360-361 (Joponese Union of Sport Sciences, Tokyo 1966).

Nowocki, P. E., Adom, K., Krause, R., and Ritter, V. (1971b) Die Spiroergometrie im neuen Untersuchungs-System fur den Spitzensport. Troiner-Joumal Rudersoort, 26: I-VI.

Nowacki, P. E., Krouse, R., and Adam, K. (1969) Moximal oxygen uptake by the rowing crew winnig the Olympic gold medal in 1968. Pflugers Archiy, 312: R66-R67.

Nowrocki, P. E., Krouse, R., Adom, K.,, and Ruluffs, M. (19710) Uber die cordiopulmonale Leistungsfahigkeit des Deutschlond - Achtus vor seinem Olympiosieg 1968. Sportarzt und Soortmedizin, 10:227-229.

Orfelt, L. (1970) Metobolism of 1 (+)-loctote in human skeletal muscle during exercise. Acto Physiologico Scoondinavico, 338 (Suppl.): 1-66.

Polinski, W. J. (1976) Indirect determination of oxygen deficit during moximal ergometric rowing. Mosters Thesis (Ohio University, Athens, Ohio 1976).

Pruett, E. D. R.(1977), in Astrond and Rodohl (Eds) Iextboak of Hork Physiology, figs 16-19 (McGrow-Hill, New York 1977).

Soltin, B., and Astrond, P. 0. (1967) Maximol oxygen uptake in othletes. Journal of Apolied Physiology, 23: 353-358.

Schnefder, E. (1980) Leistungsanalyse bei Rudermannschaften (limpert Verlag, Bad Hamburg 1980).

Scholander, P. F. (1947) Analyzer for occurate estimation of repiratory gases in one-half cubic centimeter somples. Journel of Biological Chemistry, 167:235-249.

Secher, N. H. (1983) The physiology of rowing. Journol of Sports Sclences, 1 : 23-53. 
Secher, N. H., Espersen, M., Binkhorst, R. A., Andersen, P. A., and Rube, N. (1982) Aerobic power at the onset of maximal exercise. Scandinavion Joumal of Sport Sciences, 4: 12-16.

Secher, N. H., Rube, N., and Secher, 0. (1982) Effect of tubocurorine on human soleus and gastronemius muscles. Acto Anoesthesiologice Scondnoyico 26 , 231-234.

Spitzer, J, J. (1974) Effect of lactote infusion of conine myocordiol free fotty ocid metobolism in vivo. American Joumal of Physiology, 226: 213-217.

Voage, 0. (1977) in Astrond and Rodohl (Eds) Textbook of Work Physiology table 16-2 (McGraw-Hill, New York 1977).

Wasserman, K., Whipp, B. J., Koyal, S. N., and Beaver, W. L. (1973) Anaerobic threshold and respiratory gas exchange during exercise. Journal of Applied Physiology, 35: 236-243.

Whipp, B. J., Word, S. A., LoMarro, N., Dovis, J. A., and Wosserman, K. (1982) Parameters of ventilotory and gas exchange dynamics during exercise. Journal of Applied Physiology, 52, 1506-1513.

Williams, L. R. T. (1976) Work output and heort rote response in top level New Zeoland oorsmen. Research Querterly, 47: 506-512.

Yomakawo, J., and Ishiko, T. (1966) Standardization of physical fitness tests for oorsmen: in Kato (Ed.) Proceedings of Internotional Congress of Sports Sciences, Tokyo, October, 1964, Dp. 435-436 (Japonese Union of Sport Sciences, Tokyo 1966). 